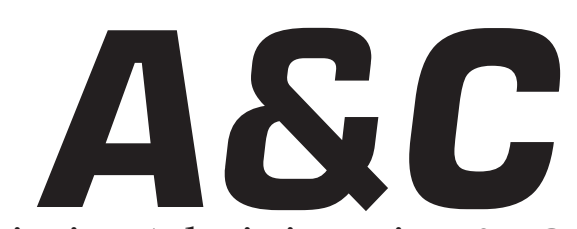

Revista de Direito Administrativo \& Constitucional

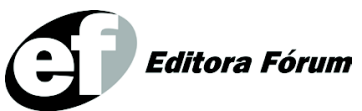

ISSN 1516-3210

A\&C R. de Dir. Administrativo e Constitucional Belo Horizonte ano 7 n. 29 p. $1-250$ jul./set. 2007 


\section{A\&C REVISTA DE DIREITO ADMINISTRATIVO E CONSTITUCIONAL}

IPDA

Instituto Paranaense

de Direito Administrativo

Direção Geral

Romeu Felipe Bacellar Filho

Direção Editorial

Paulo Roberto Ferreira Motta

Direção Executiva

Emerson Gabardo

Conselho de Redação

Edgar Chiuratto Guimarães

Adriana da Costa Ricardo Schier

Célio Heitor Guimarães

\section{Conselho Editorial}

Jorge Luís Salomoni - in memoriam (Argentina)

José Carlos Abraão (Brasil)

José Carlos Abraão (Brasil)
José Eduardo Martins Cardoso (Brasil)

José Luís Said (Argentina)

José Mario Serrate Paz (Uruguai)

Juan Pablo Cajarville Peruffo (Uruguai)

Juarez Freitas (Brasil)

Julio Rodolfo Comadira - in memoriam

(Argentina)

Luís Enrique Chase Plate (Paraguai)

Lúcia Valle Figueiredo (Brasil)

Manoel de Oliveira Franco Sobrinho

in memoriam - (Brasil)

Marçal Justen Filho (Brasil)

Marcelo Figueiredo (Brasil)

Márcio Cammarosano (Brasil)
Maria Cristina Cesar de Oliveira (Brasil)

Nelson Figueiredo (Brasil)

Odilon Borges Junior (Brasil)

Pascual Caiella (Argentina)

Paulo Eduardo Garrido Modesto (Brasil)

Paulo Henrique Blasi (Brasil)

Paulo Neves de Carvalho - in memoriam

(Brasil)

Paulo Ricardo Schier (Brasil)

Pedro Paulo de Almeida Dutra (Brasil)

Regina Maria Macedo Nery Ferrari (Brasil)

Rogério Gesta Leal (Brasil)

Rolando Pantoja Bauzá (Chile)

Sérgio Ferraz (Brasil)

Valmir Pontes Filho (Brasil)

Yara Stropa (Brasil)

Weida Zancaner (Brasil)

A246 A\&C Revista de Direito Administrativo e Constitucional. ano 3, n. 11, jan./mar. 2003. Belo Horizonte: Fórum, 2003.

Trimestral

ano 1, n.1, 1999 até ano 2, n.10, 2002 publicada pela Editora Juruá em Curitiba

ISSN 1516-3210

1. Direito Administrativo. 2. Direito Constitucional. I. Fórum.

CDD: 342 CDU: 33.342

C 2007 Editora Fórum Ltda.

Todos os direitos reservados. É proibida a reprodução total ou parcial, de qualquer forma ou por qualquer meio eletrônico ou mecânico, inclusive através de processos xerográficos, de fotocópias ou de gravação, sem permissão por escrito do possuidor dos direitos de cópias (Lei $n^{\circ}$ 9.610, de 19.02.1998).

Editora Fórum Ltda.

Av. Afonso Pena, 2770 - 15\% $16^{\circ}$ andar - Funcionários

CEP 30130-007 - Belo Horizonte/MG - Brasil

Tel.: 08007043737

Internet: www.editoraforum.com.br

e-mail: editoraforum@editoraforum.com.br
Editor responsável: Luís Cláudio Rodrigues Ferreira Coordenação editorial: Olga M. A. Sousa

Projeto gráfico e diagramação: Luis Alberto Pimenta

Revisora: Bárbara Christiane

Pesquisa jurídica: Fátima Ribeiro - OAB/MG 74868

Bibliotecária: Leila Aparecida Anastácio - CRB 2809/MG 6a região

Os conceitos e opiniões expressas nos trabalhos assinados são de responsabilidade exclusiva de seus autores.

Impressa no Brasil / Printed in Brazil

Distribuída em todo o Território Nacional 


\title{
El principio de proporcionalidad en el Derecho Administrativo Español
}

\author{
Juan Francisco Pérez Gálvez \\ Profesor Titular de Derecho Administrativo de la Universidad de Almería (España).
}

Palabras clave: Derecho penal. Derecho comparado. Derecho constitucional. Principio de proporcionalidad. Derecho administrativo.

\begin{abstract}
Sumario: I Ideas generales - 1 Antecedentes del principio de proporcionalidad - 2 El principio de proporcionalidad en la actualidad y en el Derecho comparado - II El principio de proporcionalidad como principio constitucional y como principio general del Derecho - $1 \mathrm{El}$ reconocimiento de un doble valor - 2 Fundamentos constitucionales del principio de proporcionalidad - 3 El principio de proporcionalidad como un principio general del derecho - III Elementos que conforman este principio - 1 Enumeración 2 La idoneidad o juicio de adecuación - 3 La necesidad o juicio de indispensabilidad - La proporcionalidad en sentido estricto - IV El principio de proporcionalidad en la Ley de Régimen Jurídico de las Administraciones Públicas y del Procedimiento Administrativo Común - 1 Consideraciones preliminares - 2 Proporcionalidad y ejecución forzosa de actos administrativos - 3 Proporcionalidad y su aplicación en el derecho administrativo sancionador - 4 A modo de resumen - V Final
\end{abstract}

\section{Ideas generales}

\section{Antecedentes del principio de proporcionalidad}

La formulación inicial del principio de proporcionalidad se encuentra en el ámbito del Derecho penal, en relación con la determinación de la pena Ya Beccaria hizo referencia la proporcionalidad en el orden punitivo en su obra De los delitos y las penas, en la que propugnaba que la "pena proporcional a la culpabilidad era la única pena útil”. Igualmente se reconoce este principio en la Declaración de Derechos del Hombre y del Ciudadano de 1789, que proclamaba que la Ley no debía establecer otras penas que las estricta y evidentemente necesarias.

La nueva concepción liberal del Estado y de la actividad de policía que surge en el siglo XIX, caracterizada por el reforzamiento de la protección de las esferas jurídicas individuales mediante el reconocimiento de una serie de derechos que limitan la intervención del Estado en el ejercicio de su potestad de policía, determina un claro desarrollo del principio. De manera que la actividad de policía no se concibe como un poder ilimitado, sino que se van configurando una serie de normas y principios de los que deriva que las intervenciones policiales sólo son lícitas en la medida en que son imprescindibles y adecuadas a los fines que persiguen. 
La doctrina alemana da buena cuenta del principio que estamos estudiando, y en la obra de Otto Mayer se determina que la regla de la proporcionalidad se configura como una "medida natural" de la potestad de policía, adquiriendo la importancia de un verdadero límite jurídico. También Merkl, al referirse a los medios de los que puede valerse la policía, afirma que del principio de proporcionalidad se deriva que la intervención policial debe guardar proporción con el mal que se trata de evitar, y que la autoridad debe elegir aquellos medios que menos daños produzcan a los derechos e intereses de los individuos; finalmente, Fleiner, sostenía, también en relación con el poder de policía, que la limitación individual no debe exceder jamás de la medida absolutamente necesaria, y que la intervención gubernativa ha de ser siempre proporcionada a las circunstancias concurrentes en cada caso.

Es, por tanto, esta concepción de la actividad de policía, la finalidad de proteger al individuo frente a las posibles intervenciones excesivas del Estado y de reducir su actuación a lo estrictamente necesario, la que da lugar a que con cada vez más frecuencia, tanto la doctrina como la jurisprudencia, - no sin discrepancias, recurran a este principio, inicialmente en relación con las manifestaciones de la actividad administrativa vinculadas con el ejercicio de las potestades sancionadoras, - en materia de orden público seguridad -, para pasar, posteriormente, a utilizarse respecto las demás intervenciones administrativas que inciden en la esfera de libertad de los particulares. ${ }^{1}$

\section{El principio de proporcionalidad en la actualidad y en el Derecho comparado}

Actualmente, el principio de proporcionalidad ha experimentado un auge extraordinario, y su utilización se ha generalizado en casi todas las esferas jurídicas, ${ }^{2}$ en particular, en el derecho administrativo, en el que se ha convertido en un principio rector fundamental que opera como un límite material en aquella actividad estatal que actúa sobre el ámbito de libertad de los ciudadanos, y

\footnotetext{
1 Vide Isabel PERELLO DOMENECH, "El principio de proporcionalidad y la jurisprudencia constitucional", Jueces para la democracia, 28, (1997), p. 69.

2 Vide Javier BARNES, "El principio de proporcionalidad. Estudio preliminar", Cuadernos de Derecho Público, 5, (1998), p. 15-16: "El principio de proporcionalidad - como principio jurídicamente exigible - representa una pequeña pieza dentro de un sistema, de un universo más amplio, en el que se enmarca y al que pertenece, como el que encarnan la teoría general de los derechos fundamentales y de los límites frente a la actividad limitadora del legislador y de los demás poderes públicos; las técnicas de control judicial, el canon de constitucionalidad, etc. El entendimiento del principio será, pues, en primer término, tributario de esa concepción general en la que hunda sus raíces. Pero, al mismo tiempo, el examen al microscopio de su estructura interna evidencia de inmediato la complejidad y hondura dogmática que su fisiología encierra, como por demás acreditan la abundante literatura y jurisprudencia de los últimos decenios en tantos países occidentales".
}

A \& C R. de Dir. Administrativo e Constitucional, Belo Horizonte, ano 7, n. 29, p. 171-186, jul./set. 2007 
además se configura como un instrumento eficaz en el control jurídico material de las decisiones discrecionales.

La Carta de Derechos Fundamentales de la Unión Europea, en su art. 52, menciona de forma expresa el principio de proporcionalidad como límite de los límites a los derechos en ella reconocidos:

Cualquier limitación del ejercicio de los derechos y libertades reconocidos por la presente Carta deberá ser establecida por la ley y respetar el contenido esencial de dichos derechos y libertades. Sólo se podrán introducir limitaciones, respetando el principio de proporcionalidad, cuando sean necesarios y responda efectivamente a objetivos de interés general reconocidos por la Unión, o a la necesidad de protección de los derechos y libertades de los demás.

Algunos ordenamientos europeos, ${ }^{3}$ como el alemán, y el suizo, reconocen expresamente este principio, cuya existencia deriva del propio Derecho Constitucional. En otros ordenamientos como en el francés, no se reconoce de manera expresa su existencia si bien la jurisprudencia utiliza con frecuencia la proporcionalidad en el enjuiciamiento del eventual exceso de las medidas de policía. Así, el Consejo de Estado francés, en el ya clásico arret Bejamin - 19 de mayo de 1933 —, realizó un control de proporcionalidad en relación con una medida de policía. En esta decisión el Consejo de Estado anula una prohibición de un alcalde para la celebración de una conferencia de carácter literario porque de la instrucción no resultaba que la eventualidad de desórdenes presentara una gravedad tal que, sin prohibir la conferencia, se habría podido mantener el orden adoptando medidas de policía adecuadas. Posteriormente, se ha aplicado este principio en el control de las intervenciones administrativas en otros ámbitos, como en el derecho público económico, incidiendo el Consejo de Estado francés en la necesidad de justificar la adecuación de las medidas al fin perseguido. Para ello ha utilizado nuevas técnicas del control de la proporcionalidad articuladas sobre la tesis del balance de costes-beneficios, fundamentalmente para el enjuiciamiento de aquellas decisiones arbitrarias o irrazonables que comportan un coste social elevado y desprovisto de justificación.

Tampoco en el sistema administrativo inglés hay un reconocimiento explícito de la proporcionalidad, si bien, a menudo se recurre a la teoría de la racionalidad y de los límites del poder discrecional. Igual sucede en el derecho administrativo italiano, en el que junto al principio de proporcionalidad aparecen otros conceptos similares como el de adecuación y el de racionalidad.

La proporcionalidad encuentra su consagración en el Convenio Europeo

\footnotetext{
${ }^{3}$ Vide Markus GONZÁLEZ BEILFUSS, El principio de proporcionalidad en la jurisprudencia del Tribunal Constitucional, Thomson-Aranzadi, Pamplona, 2003, p. 22, donde explicita referencias constitucionales de distintos países que incorporan a su carta magna el principio de proporcionalidad.
}

A \& C R. de Dir. Administrativo e Constitucional, Belo Horizonte, ano 7, n. 29, p. 171-186, jul./set. 2007 
de Derechos Humanos y Libertades Fundamentales, en la medida que las injerencias a las libertades que consagra sólo son admisibles en cuanto constituyen medidas necesarias en una sociedad democrática para los objetivos que se precisan en el apartado segundo de los artículos 8, 9, 10 y 11 del Convenio. Es decir, pese a omitir cualquier referencia expresa al principio de proporcionalidad, establece una serie de exigencias para la limitación de los derechos individuales que tienen una evidente conexión con dicho principio. Por un lado cuestiona qué medios pueden ser utilizados para la consecución de un determinado fin y, por otro, establece restricciones - en el ámbito de la protección de los derechos humanos - a las limitaciones de los derechos de libertad, a fin de que éstas guarden una razonable relación entre los fines perseguidos y los medios utilizados para su consecución. Por ello llegamos a la conclusión de que su contenido puede considerarse implícito en diversas reglas del CEDH. ${ }^{4}$

También el artículo 15 CEDH contiene una formulación que ha conducido al Tribunal a la aplicación del principio de proporcionalidad. Este precepto, permite a los Estados limitar los derechos y libertades reconocidos en el Convenio en caso de guerra o de otro peligro público en la medida en que resulte estrictamente indispensable a la vista de las circunstancias concretas. ${ }^{5}$

Y el Tribunal Europeo de Derechos Humanos, en su jurisprudencia, ha operado con frecuencia con la proporcionalidad para el control de las intervenciones de los Estados miembros, en la protección de los derechos y libertades fundamentales que reconoce la Convención. En este sentido, el Tribunal de Estrasburgo ha manifestado que los Estados miembros tienen un margen de libertad para elegir las medidas y restricciones que juzguen necesarias, y se ha limitado a comprobar si en cada caso se respetan las exigencias derivadas de la proporcionalidad. En concreto, ha examinado si la intervención estatal persigue algún fin legitimado en la Convención, y además si la medida restrictiva es necesaria, útil y proporcionada (casos Dudgeon, Silver y otros, Barthold). De sus decisiones se advierte claramente que el Tribunal Europeo aplica el principio de proporcionalidad en la protección de los derechos y libertades garantizados en el Convenio, determinando a su vez una clara influencia a los tribunales nacionales que tienen encomendada

\footnotetext{
4 Vide Bardo FASSBENDER, "El principio de proporcionalidad n la jurisprudencia del Tribunal Europeo de Derechos Humanos", Cuadernos de Derecho Público, 5, (1998), p. 52: "Así se advierte, por ejemplo, en los artículos 8 a 11 del CEDH, en los que se garantiza la protección de la esfera privada (art. 8), la libertad de pensamiento, conciencia y religión (art. 9), la libertad de expresión (art. 10), y la libertad de reunión y asociación (art. 11). En todos estos preceptos, después del reconocimiento genérico del derecho fundamental, se establece - en el apartado segundo del correspondiente artículo - un límite basado en el interés general y vinculado a los concretos fines admisibles en cada uno de los supuestos"...

5 Vide Manuel MEDINA GUERRERO, "El principio de proporcionalidad y el legislador de los derechos fundamentales", Cuadernos de Derecho Público, 5, (1998), p. 119-141.
} 
la salvaguarda de los derechos y libertades públicas. ${ }^{6}$

Sin embargo, y a pesar de todas las consideraciones expuestas, se trata de un principio que también ha cosechado críticas por parte de la doctrina: “escapa a cualquier intento de aplicación racional debido a su escasa claridad conceptual, a la carencia de puntos de referencia jurídicos que sustenten su aplicación en el ámbito de los derechos fundamentales, a la inconmensurabilidad y dificultad para identificar los bienes y derechos que se enfrentan en la ponderación y, finalmente, al riesgo de desembocar en una jurisprudencia puramente casuística". ${ }^{7}$

\section{El principio de proporcionalidad como principio constitucional y como principio general del Derecho}

\section{El reconocimiento de un doble valor}

Tal y como ha sido señalado el Convenio Europeo de Derecho Humanos ofrece fuertes apoyos en su propio articulado. En el Derecho Comunitario el principio ha adquirido, desde la década de los setenta del siglo anterior, una importancia extraordinaria para proyectarse en todos los ámbitos. La proporcionalidad comunitaria y nacional no se solapan ni interfieren habida cuenta de que el término de comparación se rige por su respectivo marco u ordenamiento. Así, la primera se refiere siempre a los derechos e intereses reconocidos por el Derecho Comunitario, cualquiera que sea el origen de la intervención pública, estatal o comunitaria. ${ }^{8}$

Desde sus inicios, tanto la jurisprudencia del Tribunal Constitucional ${ }^{9} \mathrm{Como}$ del Tribunal Supremo han aplicado este principio con notable éxito, exigiendo a todos los poderes públicos la estricta observancia del mismo.

El Tribunal Constitucional, aunque con referencia exclusivamente al principio de proporcionalidad de la pena, ha planteado en la sentencia 65/1986, de 22 de mayo, las siguientes consideraciones:

[...] problema distinto sería examinar si el principio de proporcionalidad de la pena puede considerarse consagrado por otros preceptos constitucionales. Especialmente los que constituyen a España como Estado de Derecho y proclaman la justicia como valor superior de su ordenamiento jurídico (art. 1) y el que establece la dignidad de la persona humana y los derechos que le son inherentes son fundamento del orden político y de la paz social (art. 10) podrían invocarse

\footnotetext{
6 Vide Isabel PERELLO DOMENECH, "El principio de proporcionalidad y la jurisprudencia constitucional", Jueces para la democracia, 28, (1997), p. 69 y 70.

7 Vide Gloria-Patricia LOPERA MESA, "El principio de proporcionalidad y los dilemas del constitucionalismo", Revista Española de Derecho Constitucional, 73, (2005), p. 387.

8 Vide Javier BARNES, "El principio de proporcionalidad. Estudio preliminar", Cuadernos de Derecho Público, 5, (1998), p. 23.

9 Vide Carolina PEREIRA SAEZ, "Una contribución al estudio del empleo del principio de proporcionalidad en la jurisprudencia reciente del Tribunal Constitucional español", Anuario de la Facultad de Derecho de la Universidad de La Coruña, 2004, p. 1043-1060.
} 
como argumentos a favor de que nuestra Constitución consagra esa idea de proporcionalidad de la pena [...] (Fundamento Jurídico Segundo).

En base a estas afirmaciones es posible el reconocimiento del principio de proporcionalidad con un doble valor, como "principio constitucional" en determinados ámbitos de aplicación (en el penal; en la protección y garantía de los derechos fundamentales; en la protección de bienes e intereses constitucionalmente reconocidos; etc.), y como "principio general del Derecho" ${ }^{10}$ en los demás ámbitos de aplicación. ${ }^{11}$

\section{Fundamentos constitucionales del principio de proporcionalidad}

En base a estos presupuestos, La doctrina ${ }^{12}$ ha señalado los fundamentos constitucionales del principio de proporcionalidad en la actividad administrativa, a saber:

- El principio de "Favor Libertatis" expresión del valor de la libertad y de la dignidad de la persona-, como exigencia constitucional del principio de proporcionalidad de la actividad administrativa.

- La justicia material - expresión del Estado de Derecho - como exigencia constitucional del principio de proporcionalidad de la actividad de la Administración.

- La delimitación constitucional del comportamiento del sector público económico, según el principio de proporcionalidad: necesaria adecuación de medios y fines.

- La misión constitucional de "servir con objetividad los intereses generales", justificadora del sometimiento de la Administración al principio de proporcionalidad.

- El control jurisdiccional del sometimiento de la actuación administrativa a los fines que la justifican, fundamenta un control de proporcionalidad.

- El principio de autonomía territorial que la Constitución garantiza, postula la utilización del principio de proporcionalidad en las relaciones interadministrativas.

3 El principio de proporcionalidad como un principio general del derecho Así lo ha establecido el Tribunal Supremo al determinar:

\footnotetext{
10 Vide STC 62/1982, de 15 de octubre: "[...] para determinar si las medidas aplicadas eran necesarias para el fin perseguido, hemos de examinar si se han ajustado o si han infringido el principio de proporcionalidad. La Sala no ignora la dificultad de aplicar en un caso concreto un principio general del derecho que, desde su formulación como concepto jurídico indeterminado, permite un margen de apreciación [...]".

${ }^{11}$ Vide José Ignacio LÓPEZ GONZÁLEZ, El principio general de proporcionalidad en derecho administrativo, Instituto García Oviedo, Sevilla, 1988, p. 60.

12 Ibídem, p. 76-89.
}

A \& C R. de Dir. Administrativo e Constitucional, Belo Horizonte, ano 7, n. 29, p. 171-186, jul./set. 2007 
Los principios generales del Derecho, esencia del Ordenamiento jurídico, son la atmósfera en la que se desarrolla la vida jurídica, el oxígeno que respiran las normas, lo que explica que tales principios informen las normas - artículo 1.4 del Título Preliminar del Código Civil - y que la Administración esté sometida no sólo a la ley sino también al Derecho - artículo 103.1 de la Constitución. $\mathrm{Y}$ es claro que si tales principios inspiran la norma habilitante que atribuye una potestad a la Administración, esta potestad ha de actuarse conforme a las exigencias de los principios.

Uno de estos principios reiteradamente invocado por la jurisprudencia, es el de proporcionalidad, que deriva claramente del artículo 106.1 de la Constitución que al dibujar el control jurisdiccional de la Administración alude al sometimiento de la actuación administrativa a los fines que la justifican: aunque en ocasiones este precepto se ha entendido como una alusión a la desviación de poder, su sentido en muchos más amplio y recoge la necesidad de una armonía entre los medios utilizados y la finalidad perseguida. En la misma línea, el principio de proporcionalidad tiene expresión en los artículos 84.2 de la Ley reguladora de las Bases del Régimen Local 7/1985, ${ }^{13}$ y 6 del Reglamento de Servicios de las Corporaciones Locales. ${ }^{14}$

El principio de proporcionalidad, en lo que ahora importa, opera en dos tipos de supuestos:

a) Con carácter ordinario, en aquellos casos en los que el Ordenamiento jurídico admite la posibilidad de elegir uno entre varios medios utilizables.

b) Ya con carácter excepcional y en concesión con los principios de buena fe y equidad, en los supuestos en los que aun existiendo en principio un único medio éste resulta a todas luces inadecuado y excesivo en relación con las características del caso contemplado. ${ }^{15}$

\footnotetext{
${ }^{13}$ Vide Ley 7/1985, de 2 de abril, reguladora de las Bases del Régimen Local, art. 84.2: "La actividad de intervención se ajustará, en todo caso, a los principios de igualdad de trato, congruencia con los motivos y fines justificativos y respeto a la libertad individual".

14 Vide Decreto de 17 de junio de 1955, Reglamento de Servicios de las Corporaciones Locales, art. 6: "1. El contenido de los actos de intervención será congruente con los motivos y fines que los justifiquen. 2. Si fueren varios los admisibles, se elegirá el menos restrictivo de la libertad individual". Sobre el particular Vide José Ignacio LÓPEZ GONZÁLEZ, El principio general de proporcionalidad en derecho administrativo, Instituto García Oviedo, Sevilla, 1988, p. 20: "La jurisprudencia y la doctrina han visto en este precepto una aplicación progresista — dada la fecha de publicación del citado Reglamento, 1955- del principio de proporcionalidad, en el ámbito de las actividades de los entes locales. El artículo 6 del Reglamento de Servicios positiviza dos aspectos fundamentales del principio de proporcionalidad: la regla de adecuación del contenido de los actos con los motivos y fines que lo justifican (principio de adecuación de la medida); y elección del medio menos restrictivo (principio "pro libertate", "pro activitate" o "favor libertatis"). El precepto, dado el carácter del título primero del Reglamento de Servicios y la calidad en su conjunto de la citada disposición, ha ejercido una importante función informadora e interpretativa — no obstante su naturaleza reglamentaria- de la regulación y control de las actividades administrativas de intervención de las entidades locales en las actividades privadas".
} 


\section{Elementos que conforman este principio}

\section{Enumeración}

El principio de proporcionalidad en su sentido amplio se compone de tres elementos o subprincipios: a) el de la utilidad o adecuación; b) el de la necesidad o indispensabilidad; c) el de proporcionalidad stricto sensu. ${ }^{16}$

Cada uno de estos elementos que lo integran requiere un juicio o análisis en su concreta aplicación que implica un enjuiciamiento de la medida desde tres puntos de vista diferentes: la medida enjuiciada ha de ser idónea en relación con el fin, esto es, es preciso que al menos facilite o tienda a la consecución del objetivo propuesto (juicio de adecuación) en segundo lugar, la media ha de ser necesaria, o la más moderada de entre todos los medios útiles, en el sentido de que no sólo ha de comprobarse si la acción se legitima por el fin en cuanto susceptible de alcanzarlo, sino que además es imprescindible porque no hay otra más suave o moderada a tal propósito (juicio de indispensabilidad), y, finalmente, proporcionada, esto es, ponderada o equilibrada por derivarse de ella más beneficios y ventajas que perjuicios sobre otros bienes o valores en conflicto, en particular sobre los derechos y libertades, es decir, es preciso que la medida enjuiciada sea también razonablemente proporcionada en relación con el valor político y social que se busca con la finalidad perseguida (proporcionalidad stricto sensu). ${ }^{17}$

\section{La idoneidad o juicio de adecuación}

Para comprobar la utilidad o idoneidad de una medida restrictiva de un derecho habrá de verificarse, inicialmente, si es apta para la consecución del fin perseguido. En efecto, lo primero que habrá de comprobar es si la medida enjuiciada supera el oportuno juicio de adecuación, o, en otras palabras, si la relación medio-fin resulta adecuada e idónea. Es preciso, por tanto, que la restricción que sufre el derecho resulte realmente útil para justificar el fin perseguido, o, dicho en negativo que la medida restrictiva no sea desde todo punto de vista, y en principio, absolutamente inútil para alcanzar el fin. ${ }^{18}$

\section{La necesidad o juicio de indispensabilidad}

Una vez constatada la existencia de una adecuada relación medio-fin, esto es, superado el test de adecuación, el análisis debe recaer sobre la necesidad de la

\footnotetext{
${ }^{15}$ Vide STS de 16 de mayo de 1990, Ar. 4167.

${ }^{16}$ Vide: Javier BARNES, "Introducción al principio de proporcionalidad en el derecho comparado y comunitario", $R A P, 135,(1994)$, p. 521-530; Juan RIVERO LAMAS, "Principio de proporcionalidad y derechos fundamentales (sobre la inconstitucionalidad de la filmación de los piquetes en una huelga), Revista Española del Derecho del Trabajo, 98, (1999), p. 932-934.

${ }^{17}$ Vide Isabel PERELLO DOMENECH, "El principio de proporcionalidad y la jurisprudencia constitucional", Jueces para la democracia, 28, (1997), p. 70.

18 Ibídem, p. 70.
}

A \& C R. de Dir. Administrativo e Constitucional, Belo Horizonte, ano 7, n. 29, p. 171-186, jul./set. 2007 
medida enjuiciada. Ello implica examinar si la intervención pública es indispensable, por no existir un instrumento más moderado para su consecución.

De entre los diversos medios posibles, habrá de optarse por aquel que implique una menor restricción en la esfera jurídica de los afectados, esto es, que no se imponga un sacrificio claramente innecesario por existir otra alternativa menos gravosa que puede satisfacer igual objetivo. Por tanto, de entre las posibles alternativas, deberá elegirse siempre aquella menos gravosa o restrictiva de los derechos; para ello habrá que confrontar los diversos medios igualmente idóneos y aptos para la consecución del fin, y determinar aquélla que resulte menos onerosa, siempre que existan otras alternativas que garanticen de modo satisfactorio el objeto que justifique el límite, por consiguiente, han de rechazarse las medidas más gravosas y elegir el medio más beneficioso. ${ }^{19}$

\section{La proporcionalidad en sentido estricto}

Finalmente, superados los anteriores juicios de idoneidad y necesidad, debe comprobarse si existe un equilibrio entre las ventajas y perjuicios que se generan por la limitación de un derecho para la protección de otro bien o derecho constitucionalmente protegido. Para ello, resulta inevitable valorar los diferentes intereses contrapuestos y las circunstancias concurrentes en cada caso. Los beneficios y ventajas derivados de la restricción del derecho deben ser siempre superiores a los perjuicios sobre otros bienes o intereses en conflicto. Debe existir una ponderación entre las ventajas y los perjuicios que se generan cuando se limita un derecho a fin de proteger otro derecho o bien constitucionalmente protegido, tomando en consideración las circunstancias relevantes en cada caso. En definitiva, ello implica que los medios elegidos deban mantenerse en una relación razonable con el resultado perseguido. ${ }^{20}$

\section{El principio de proporcionalidad en la Ley de Régimen Jurídico de las Administraciones Públicas y del Procedimiento Administrativo Común \\ 1 Consideraciones preliminares}

La legislación estatal se ha limitado esporádicamente a recoger algunas manifestaciones parciales de la regla de la proporcionalidad, en relación con la actividad administrativa. Por vía meramente ejemplificativa cabe citar entre otras disposiciones las siguientes: el artículo 40.2 de la Ley de Procedimiento Administrativo "el contenido de los actos se ajustará a lo dispuesto en el ordenamiento

\footnotetext{
${ }^{19}$ Ibídem, p. 70.

${ }^{20}$ Ibídem, p. 70.

A \& C R. de Dir. Administrativo e Constitucional, Belo Horizonte, ano 7, n. 29, p. 171-186, jul./set. 2007
} 
jurídico y será adecuado a los fines de aquéllos”; el artículo 15 de la Ley de Expropiación Forzosa "declarada la utilidad pública o el interés social, la Administración resolverá sobre la necesidad concreta de ocupar los bienes o adquirir los derechos que sean estrictamente indispensables para el fin de la expropiación [...]".

La Administración, siempre y en todo caso, ha de adecuar su actuación a la ley y al derecho (art. 103.2 CE), una regla en la sería erróneo ver redundancia, pues el derecho y la ley expresan conceptos distintos por más que la relación entre ellos existe, y no puede dejar de existir, porque el derecho es algo así como la linfa vital de la que se nutre la ley.

En ese artículo 103.2 CE (y también en el artículo 3, LRJPAC), ${ }^{21}$ aparecen claramente distinguidos el derecho "puesto", o sea el derecho positivo, y ese otro derecho que sirve de fundamento de aquél, y que son los llamados principios generales.

Pues bien, hay por lo menos dos de esos principios que en la ejecución forzosa cobran particular importancia: el de proporcionalidad y el de opción pro libertate (a ellos me referiré más adelante).

El principio de proporcionalidad es un principio general del derecho que emerge ocasionalmente en diversos sectores de nuestro derecho positivo, aunque, en cuanto principio general que es, aun cuando no se declare expresamente, es de exigible aplicación.

\section{Proporcionalidad y ejecución forzosa de actos administrativos}

En la Exposición de Motivos de la LRJPAC, apartados 12 y 14, destaca la formulación del principio de proporcionalidad en los siguientes términos: ${ }^{22}$

La autotutela de la Administración Pública, potestad que permite articular los medios de ejecución que garanticen la eficacia de la actividad administrativa, queda en todo caso subordinada a los límites constitucionales, debiendo adoptarse los medios precisos para la ejecución, de modo que se restrinja al mínimo la libertad individual y de acuerdo con el principio de proporcionalidad.

El Título IX regula los principios básicos a que debe someterse el ejercicio de la

\footnotetext{
${ }^{21}$ Vide Ley 30/1992, de 26 de noviembre, de Régimen Jurídico de las Administraciones Públicas y del Procedimiento Administrativo Común, art. 3: "Principios generales. 1. Las Administraciones públicas sirven con objetividad los intereses generales y actúan de acuerdo con los principios de eficacia, jerarquía, descentralización, desconcentración y coordinación con sometimiento pleno a la Constitución, a la Ley y al Derecho. [...]".

22 Vide José Ignacio LÓPEZ GONZÁLEZ, "El principio de proporcionalidad en Derecho Administrativo", Cuadernos de Derecho Público, 5, (1998), p.157-158: "Se echa de menos en el Título Preliminar de la Ley 30/1992, un precepto que consagre el principio de proporcionalidad en el ámbito general de las relaciones de la Administración con los particulares (lo que no se satisface desde la óptica del artículo 96.2 de dicha Ley), integrando así las determinaciones del actual artículo 6 del Reglamento de Servicios de las Corporaciones Locales, que un tanto forzadamente se ve obligada la jurisprudencia a citar y aplicar a todas las Administraciones Públicas, dado que la virtualidad del principio general que se garantiza en dicho precepto desborda la naturaleza del mismo".
} 
potestad sancionadora de la Administración [...]. Entre tales principios destaca el de legalidad [...] y el de proporcionalidad [...]. Todos ellos se consideran básicos al derivar de la Constitución y garantizar a los administrados un tratamiento común ante las Administraciones Públicas [...].

En el artículo 96.1 y 2 de la Ley 30/1992, se puede deducir que este principio en el ámbito del Derecho Administrativo, se concreta cuando el legislador lo contempla al establecer que:

1. La ejecución forzosa por las Administraciones Públicas se efectuará, respetando siempre el principio de proporcionalidad, por los siguientes medios: a) Apremio sobre el patrimonio; b) Ejecución subsidiaria; c) Multa coercitiva; d) Compulsión sobre las personas.

2. Si fueran varios los medios de ejecución admisibles se elegirá el menos restrictivo de la libertad individual.

Es decir, la ejecución forzosa es uno de esos ámbitos en que está ahora expresamente positivizado el citado principio. Además se pone de manifiesto que a la Administración (art. 96.2 LRJPAC), sin duda porque la libertad es uno de los valores constitucionales (art. $1 \mathrm{CE}$ ), a la hora de tener que optar entre diversos medios de ejecución forzosa que fueren "admisibles" deberá optar por el que resulte "menos restrictivo de la libertad individual".

En los artículos 97 a 100 el legislador determina pormenorizadamente los supuestos en los que procederá la aplicación de cada uno de esos medios de ejecución forzosa previamente enumerados. ¿Y cuál es el menos restrictivo de la libertad individual?. Suele estar bastante extendida la convicción — errónea, a mi juicio - de que es la multa coercitiva ${ }^{23}$ la menos gravosa. Y digo que es errónea esa creencia porque no se cae en la cuenta de que la multa coactiva - que es un híbrido de sanción y medida coercitiva - añade un plus obligacional a la obligación que se trata de ejecutar.

Obsérvese, ya en este momento, que el art. 96.2 LRJPAC, a más de positivizar el citado principio de proporcionalidad, prueba que no todos los medios de ejecución forzosa son utilizables a voluntad de la Administración ejecutante. Hay, en efecto, unos medios que son admisibles en un caso y pueden no serlo

\footnotetext{
${ }^{23}$ Vide STS de 10 de julio de 1984 (Ar. 5577): "[El TS rebaja la multa coercitiva, de 6.750 .000 ptas, a 2.299.170 ptas, habida cuenta que] "los informes técnicos oficiales que nos sirven de base para sostener la procedencia de esta multa, viene a proclamar que, dentro del plazo fijado por la Administración, estas empresas han acometido la realización de parte de las obras impuestas por aquélla, acabándolas incluso algunas de ellas e iniciando otras, aunque no todas; circunstancias que no deben merecer la imposición de la multa en su grado máximo [...]; rectificación que se impone para restablecer el principio de proporcionalidad entre la entidad del hecho causante y la cuantía de ésta; principio a tener en cuenta en toda actuación administrativa, pero sobre todo, en esta materia en la que el finalismo del acto no puede quedar desvinculado en ningún momento de su causa y de los presupuestos de hecho que lo determinan".
} 
en otros. Por eso el precepto alude a la posible situación de que hubiera varios medios de ejecución que ante un caso determinado puedan ser utilizados, en cuyo caso marca un criterio para elegir el más adecuado, criterio que no es otro que el de la proporcionalidad.

\section{Proporcionalidad y su aplicación en el derecho administrativo sancionador}

El principio de proporcionalidad que en materia de intervención administrativa goza de una cierta tradición en el derecho español, en el que aparece ya expresamente recogido en el Reglamento de Servicios de las Corporaciones Locales, cumple en el ámbito del derecho administrativo sancionador una doble función: por un lado sirve para introducir un criterio de prudencia en la tipificación de las conductas reprochables, de manera que sólo se califica de infracción aquellas conductas que no pueden ser reprimidas por otros medios; por otro lado - y es el aspecto que aquí interesa considerar — sirve para atemperar el ejercicio de la potestad sancionadora, transformando lo que podría verse como actividad discrecional en una actividad reglada. ${ }^{24}$

Ambos aspectos se tienen en cuenta por la LRJPAC cuando en el artículo 131.3 dice:

En la determinación normativa del régimen sancionador, así como en la imposición de sanciones por las Administraciones públicas se deberá guardar la debida adecuación entre la gravedad del hecho constitutivo de la infracción y la sanción aplicada $[\ldots]$,

Operación esta que compete originariamente al legislador estatal y autonómico. Sucede otro tanto en el artículo 131.2 cuando afirma que:

El establecimiento de sanciones pecuniarias deberá prever que la comisión de las infracciones tipificadas no resulte más beneficiosa para el infractor que el cumplimiento de las normas infringidas.

En consecuencia, nos hallamos aquí ante una consideración del principio de proporcionalidad que opera en el plano de la Ley y con carácter reglado para las Administraciones Públicas, representando además para los particulares verdaderas garantías frente a la actuación administrativa. Por todo ello la proporcionalidad debe tenerse en cuenta a los fines de determinar la sanción, puesto que "el extremismo de esa práctica legislativa y reglamentaria de poner

\footnotetext{
${ }^{24}$ Vide Jesús GONZÁLEZ PÉREZ y Francisco GONZÁLEZ NAVARRO, Comentarios a la Ley de Régimen Jurídico de las Administraciones Públicas y Procedimiento Administrativo Común (Ley 30/1992, de 26 de noviembre), Vol. II, 3. ed., Thomson-Cívitas, Madrid, 2004, p. 2.888.
} 
en manos del Gobierno y de la Administración unas prerrogativas ilimitadas en la determinación cuantitativa de las multas es lo que fuerza a la jurisdicción a no quedarse en la periferia de estos problemas (se refiere a competencias y procedimientos) y a tener que adentrarse en las entrañas de los mismos penetrando en la forma de ejercitarse". ${ }^{25}$

Estamos en efecto, ante un principio descubierto por la jurisprudencia en este campo y que es de recomendable aplicación en aquellos casos en que el legislador ha guardado silencio, y de él se ha hecho uso en más de una ocasión al controlar el ejercicio de la potestad reglamentaria, dado que "la potestad reglamentaria de la Administración no implica potestad originaria de castigar [...] y está sujeta a los principios comunes de todo ordenamiento sancionador, como, por ejemplo, la graduación proporcional de las penas". ${ }^{26}$

También se invoca el principio para anular una sanción por falta de la cobertura normativa para la misma cuando se trata de un reglamento que "dejando en blanco tanto el límite de las sanciones como las que corresponden a cada tipo de infracción, se deja en manos de la Administración la facultad de imponer la sanción con toda la amplitud permitida, sean cuales sean los hechos cometidos, con lo que las facultades de la Administración no son discrecionales sino omnímodas". ${ }^{27}$

En definitiva, lo que resulta innegable - y es, ciertamente, doctrina jurisprudencial consolidada - es que la existencia o no de proporcionalidad entre los hechos y su sanción es controlable judicialmente. ${ }^{28}$

Tras lo expuesto se verifica que los artículos 96.2 y 131.3 contemplan sendas manifestaciones del principio de proporcionalidad en la aplicación de la Ley, en los respectivos ámbitos materiales en que opera la actividad administrativa (medios de ejecución forzosa y potestad sancionadora), y en los siguientes términos:

[...] en la imposición de sanciones por las Administraciones Públicas se deberá guardar la debida adecuación entre la gravedad del hecho constitutivo de la infracción y la sanción aplicada, considerándose especialmente los siguientes criterios para la graduación de la sanción a aplicar: [...].

\section{$4 \mathrm{~A}$ modo de resumen}

La Ley 30/1992 viene a positivizar a nivel legislativo las dos manifestaciones más clásicas del principio de proporcionalidad en nuestro Derecho: la elección del medio menos restrictivo de la libertad individual y la adecuación del con

\footnotetext{
${ }^{25}$ Vide STS de 19 de mayo de 1981 (Ar. 1976).

${ }^{26}$ Vide STS de 2 de noviembre de 1981 (Ar. 4720).

27 Vide STS de 6 de febrero de 1985 (Ar. 471).

${ }^{28}$ Vide SSTS: de 1 de febrero de 1995 (Ar. 1085) y de 30 de abril de 1995 (Ar. 3081).
} 
tenido de la sanción a la gravedad del hecho constitutivo de la infracción, para cuya determinación el legislador sintetiza como criterios de especial consideración los relativos a la existencia de intencionalidad o reiteración, la naturaleza de los perjuicios causados y la reincidencia, entendida como la comisión en el término de un año de más de una infracción de la misma naturaleza, declarada por resolución firme.

Es conveniente llamar la atención acerca del criterio de adecuación que se maneja en el artículos 131.3, ya examinado, en cuanto deber legal inherente al principio de proporcionalidad.

La inadecuación entre la sanción aplicada y la gravedad del hecho constitutivo de la infracción, comporta - en el ámbito del Derecho Administrativo sancionador - la vulneración del principio de proporcionalidad, sin que sea preciso traer a colación aquí el criterio de la medida menos restrictiva de la libertad individual.

El deber legal de adecuación del contenido de todas las actuaciones administrativas a los fines previstos por el Ordenamiento jurídico, es una exigencia estricta del principio de legalidad de la Administración y en tales términos aparece recogido en diversos preceptos de la propia Ley 30/1992. Así, en el artículo 3.3 cuando afirma que:

[...] la actuación de la Administración Pública respectiva se desarrolla para alcanzar los objetivos que establecen las leyes y el resto del ordenamiento jurídico;

y de modo más concreto el artículo 53.2 establece que

[...] el contenido de los actos se ajustará a lo dispuesto por el ordenamiento jurídico y será determinado y adecuado a los fines de aquellos.

Este deber legal de adecuación que es susceptible asimismo, de otras denominaciones como idoneidad, razonabilidad, congruencia o necesidad que, en definitiva, se han de predicar del contenido de las actuaciones administrativas, por exigencias de estricta legalidad o conformidad a Derecho, precisa en muchos casos ser valorado - dada la posible complejidad de los intereses públicos concurrentes - a través de un proceso de interpretación que sólo ha sido posible realizar, tradicionalmente, acudiendo a las reglas de proporcionalidad y que hoy puede verse mejor satisfecho desde el principio general de proporcionalidad vigente en nuestro Derecho Administrativo.

La observancia del deber legal de adecuación del contenido de las actuaciones administrativas a los fines previstos por el Ordenamiento jurídico, le obliga a la Administración a operar desde el principio de proporcionalidad, cuya normatividad ha de informar las decisiones administrativas.

A \& C R. de Dir. Administrativo e Constitucional, Belo Horizonte, ano 7, n. 29, p. 171-186, jul./set. 2007 
Por otro lado, el control jurisdiccional del deber legal de adecuación fuera de los casos de arbitrariedad, prohibida por el artículo 9.3 de la Constitución - puede llevarse a cabo correctamente desde un juicio de proporcionalidad, en cuanto expresión de la función interpretativa protagonizada en el Derecho Administrativo por el principio de proporcionalidad.

En definitiva, en el plano de las relaciones Administración y administrados (actuaciones administrativas con incidencia en la esfera de libertad y patrimonial de los particulares), ${ }^{29}$ el deber legal de adecuación del contenido de las actuaciones administrativas a los fines predeterminados por el Ordenamiento jurídico, no es algo distinto del mismo principio de proporcionalidad. ${ }^{30}$

\section{Final}

La aplicación del principio de proporcionalidad en Derecho Administrativo significa que le sean jurídicamente exigibles a la Administración, como requisitos de legalidad de su actuación administrativa, los siguientes:

a) Que el contenido de la actuación administrativa sea adecuado a los fines que la justifican.

b) Que la medida adoptada sea la necesaria, por menos restrictiva y moderada, para la consecución eficaz del principio perseguido por el Ordenamiento jurídico.

c) Que la medida resulte equilibrada por derivarse de ella, para el interés general, beneficios superiores a las limitaciones o restricciones de derechos que la medida comporta.

Por todo ello se puede afirmar que el principio de proporcionalidad es un principio derivado del criterio democrático de legitimidad del Derecho que vincula, entre otros sectores, a los integrados por normas sancionadoras. El Derecho per se no es proporcionado, sino que debe serlo desde cierta perspectiva axiológica y sólo en parte de sus elementos. Es más, salvo por elipsis de elementos sobreentendidos, no cabe catalogar sin más algo como proporcionado ni cabe realizar un juicio genérico de proporcionalidad sin relación directa a otra magnitud ni

\footnotetext{
${ }^{29}$ Vide Ley 2/1998, de 15 de junio, de Salud, de Andalucía, donde se establece, en relación con las medidas obligatorias de intervención pública que se adopten en materia de salud (limitaciones, prohibiciones, medidas preventivas exigibles, etc.), que deberán adaptarse a los criterios expresados en el artículo 28 de la Ley 14/1986, de 25 de abril, General de Sanidad. Este último precepto determina que todas las medidas preventivas deben atender a los siguientes principios: "[... c) Las limitaciones sanitarias deberán ser proporcionadas a los fines que en cada caso se persigan. d) Se deberán utilizar las medidas que menos perjudiquen al principio de libre circulación de las personas y de los bienes, la libertad de empresa y cualesquiera otros derechos afectados". Se trata de un supuesto donde el principio de proporcionalidad acaba positivizándose expresamente, reforzando con ello su posición de principio general del Derecho Administrativo.

${ }^{30}$ Vide José Ignacio LÓPEZ GONZÁLEZ, "El principio de proporcionalidad en Derecho Administrativo", Cuadernos de Derecho Público, 5, (1998), p. 147-149.
} 
especificación del criterio o la medida que instrumenta la comparación. La idea de proporcionalidad pertenece a la deontología del Derecho, no a su ontología; no señala un elemento definicional, una propiedad o una consecuencia de la naturaleza del Derecho, sino una exigencia que impone un determinado criterio de justificación del mismo. ${ }^{31}$

Informação bibliográfica deste texto, conforme a NBR 6023:2002 da Associação Brasileira de Normas Técnicas (ABNT):

PÉREZ GÁLVEZ, Juan Francisco. El principio de proporcionalidad en el Derecho Administrativo Español. A\&C Revista de Direito Administrativo e Constitucional, Belo Horizonte, ano 7, n. 29, p. 171-186, jul./set. 2007.

${ }^{31}$ Vide Juan Antonio LASCURAín SÁNCHEZ, "La proporcionalidad de la norma penal", Cuadernos de Derecho Público, 5, (1998), p. 159.

A \& C R. de Dir. Administrativo e Constitucional, Belo Horizonte, ano 7, n. 29, p. 171-186, jul./set. 2007 